\title{
VARGAS LLOSA, TESTIGO DEL MUNDO
}

\author{
José Miguel Oviedo
}

La reconocida vocación realista de Vargas Llosa — se advierte en este artículo - no sólo se refleja en gran parte de sus novelas sino también en sus ensayos y obra periodística, que han ido evolucionando a partir de una inicial posición de izquierda a otra de carácter neoliberal en defensa de la libertad en todos los terrenos. A juicio de J. M. Oviedo, el gran acontecimiento que decide este cambio es su rechazo del dogmatismo y la persecución de las ideas disidentes dentro de la revolución cubana.

Un reportaje puede ser una obra de arte. (Mario Vargas Llosa, “Asesinato en Amsterdam”, El País 10 de octubre, 2006).

$\mathrm{D}$ esde sus inicios fue evidente que el arte narrativo de Mario Vargas Llosa surge de su fascinación por la realidad misma: enfrentar primero el mundo objetivo que todos experimentamos, de modo

José Miguel Oviedo. Crítico y ensayista peruano. Ha publicado numerosos trabajos sobre Vargas Llosa, García Márquez, Carlos Fuentes y otros. Autor de la Historia de la Literatura Hispanoamericana, en cuatro volúmenes. 
individual o colectivo, es indispensable para encender la chispa de su imaginación. En gran medida, su obra novelística es una reconstrucción ficticia, un fantaseo hecho a partir de elementos fácticos. Podría decirse que toda la literatura, especialmente la novela llamada "realista", existe sobre esa base, pero la diferencia aquí está en que los creadores suelen borrar esa conexión para dar mayor identidad estética a sus obras, mientras que Vargas Llosa consigue ese efecto haciendo precisamente lo contrario: subrayando la presencia de los vínculos, analogías o correspondencias entre ambos mundos.

Paradójicamente, su reelaboración del material primario con el que trabaja es muy intensa y sigue el principio de que el relato debe alcanzar una validez que, al fin y al cabo, no depende del parecido con la realidad objetiva que le da origen. Este buen discípulo de Flaubert - el novelistaartista por antonomasia - sabe que la ficción no se comporta del mismo modo que la realidad ni debe ser un mero reflejo mimético de ella.

En la veintena de novelas que el autor ha escrito hasta ahora, no creo que haya una sola, ni aun entre las más delirantes o caprichosas, que se acerque siquiera al modelo de la "novela fantástica", que parece estar lejos de tentarlo. Aprovechando imágenes, historias, personajes o experiencias propias que suelen provenir de sus años de adolescencia, supo crear un tipo de representación estética que absorbía lo real y lo trataba como ficción. Desde muy temprano, mucho antes de aprender las reglas básicas de la narración, Vargas Llosa aprendió a ser un observador de lo que ocurría a su alrededor y a registrarlo por escrito. Tuvo que hacerlo para ganarse la vida, y no por decisión propia o por razones vocacionales, pero en esa actividad descubrió significativas semejanzas y diferencias con el oficio literario, que dejarían una huella duradera en su visión de escritor. El primer campo de aprendizaje de Vargas Llosa fue el periodismo.

Cuando sólo había cumplido quince años entró a trabajar como reportero en el periódico La Crónica. Era el período de vacaciones después de su traumático paso por las aulas del colegio Leoncio Prado - a donde ya no regresaría - y de su traslado al colegio San Miguel de Piura, donde acabaría sus estudios de secundaria. Recuerdos de estas experiencias se filtrarían, como bien es sabido, en La ciudad y los perros, La casa verde y Conversación en La Catedral, aparte de figurar en su libro de memorias El pez en el agua (1994). El profundo malestar que domina en la tercera de esas novelas está dado en las memorables primeras 
líneas, en las que Zavalita contempla "sin amor" el desabrido perfil de Lima, visto desde la perspectiva del edificio de La Crónica, escena que sienta el tono preciso de lo que vendrá luego: el retrato de la frustración y mediocridad que el autor respiró en el mundillo periodístico de la época de la dictadura.

Fue su padre quien lo llevó allí para asegurarse de que el muchacho estuviese ocupado en algo "útil" durante esas vacaciones. Su iniciación periodística ha sido indagada, con minuciosidad a veces algo anecdótica, en Reportero a los quince años, libro del periodista Juan Gargurevich ${ }^{1}$. Este autor nos informa del ambiente interno y de las crónicas que el joven Vargas Llosa escribió en esos meses, especialmente las dedicadas a sangrientos sucesos policiales que los lectores de Conversación en La Catedral reconocerán fácilmente. Gargurevich incluye un dato curioso: el padre del futuro novelista desempeñaba un trabajo también asociado con el periodismo, como representante en el Perú de una agencia internacional de noticias creada por William Randolph Hearst, el magnate de la prensa en quien Orson Welles se inspiró para el filme "Citizen Kane".

Su paso por La Crónica fue breve, ya que el padre se dio cuenta de que ciertos periodistas ejercían una perniciosa influencia moral sobre el muchacho. Pese a ello, la experiencia dejó una huella profunda en él: le permitió descubrir el submundo ruin y venal (aparte de melodramático) del periodismo bajo el régimen del general Manuel A. Odría, que fue parte de su formación intelectual y de su primer contacto personal con la realidad política.

Ese aprendizaje continuó con sucesivos trabajos como redactor o colaborador de diversos periódicos y revistas locales de muy diversa naturaleza: La Industria de Piura, Extra, Turismo, Cultura Peruana, el Suplemento Dominical de El Comercio y varias otras publicaciones. Incluso hizo periodismo radial en 1957, como director de información en Radio Panamericana, experiencia que aprovecharía para crear el personaje de Pedro Camacho de La tía Julia y el escribidor. Es muy revelador que Camacho sea el modelo del "escribidor", una figura emblemática del oficio periodístico y de su relación, a la vez paralela y divergente de la actividad literaria, en medio de las carencias propias del empobrecimiento que sufría la vida cultural en esos años. Cuando ya se

\footnotetext{
${ }^{1}$ Juan Gargurevich, Mario Vargas Llosa. Reportero a los quince años,
} 2005 . 
encontraba en París, volvería a ejercer el periodismo radial, esta vez haciendo entrevistas a escritores latinoamericanos para la Radio Difusión Francesa.

En la década de los sesenta, con tres notables novelas ya publicadas y convertido en un escritor internacionalmente conocido, Vargas Llosa seguiría ejerciendo el periodismo — sobre todo cultural—, ahora en importantes periódicos y revistas de todo el mundo, que le ofrecen sus páginas conscientes del prestigio de su firma; entre ellos, Expreso y Caretas de Lima, Primera Plana de Buenos Aires, Marcha de Montevideo y Mundo Nuevo de París. Pronto esta actividad se convertiría en el vehículo habitual de una naciente obra crítica que iba a resultar muy significativa por su originalidad y abundancia. En sus primeras manifestaciones, se centra naturalmente en temas literarios; entre ellas están sus tempranos textos sobre José María Arguedas y Tirant lo Blanc, que más tarde se convertirían en libros. Su primer libro ensayístico fue García Márquez: Historia de un deicidio (1971), que es un paradigma por su rigor, exhaustividad, pasión, objetividad y, sobre todo, por una crítica al mismo tiempo que una autocrítica y un testimonio personal; posee un rasgo de la crítica que suele pasar desapercibido para algunos: el de apropiarse de una obra ajena para hablar de ella y de sí mismo. Esto se confirmaría en otros libros, desde La orgía perpetua: Flaubert y Madame Bovary (1974) hasta la reciente La tentación de lo imposible: Victor Hugo y Los miserables (2004).

Pero simultáneamente, y cada vez con mayor frecuencia, sus críticas y crónicas periodísticas fueron abarcando otros temas culturales (cine, teatro, arte, entre otros) y de actualidad social y política en América Latina y el resto del mundo, lo que le permitió intervenir en el debate de las grandes cuestiones de nuestra época, en el que dominaban unos asuntos como la Revolución Cubana y la insurgencia armada, la guerra en Argelia, los campos de concentración en la Unión Soviética, la intervención rusa en Checoslovaquia, el cisma soviético, etc. Es evidente que el periodismo era, para un escritor de ficciones con envergadura generalmente épica, una fuente para seguir alimentando su imaginación; así, podía absorber vorazmente el inagotable y siempre cambiante panorama del mundo real. Decidió no cerrar los ojos y encerrarse en su mundo interior; decidió intervenir, polemizar, tomar posiciones; decidió ser un testigo del mundo, defender ciertas ideas fundamentales, atacar otras y asumir los riesgos y responsabilidades inherentes a esa tarea. Es decir, 
prefirió ser criticado por lo que decía o escribía, y no por elegir la comodidad de callar o ignorar. En distintas épocas y con diversos matices, sus modelos han sido Sartre, Malraux, Camus, Orwell, Isaiah Berlin, Karl Popper, Ortega y Gasset y otros de esa talla.

La vastedad de esa tarea se refleja en la amplitud de la obra crítica y periodística que ha producido, con entusiasmo y tenacidad indeclinables. No es exagerado decir que el conjunto suma varios miles —quizá decenas de miles - de páginas, cifras que rivalizan con las que alcanzan sus novelas y obras teatrales. Sólo una porción de sus textos periodísticos y ensayísticos han sido recopilados en sucesivas ediciones de Contra viento y marea I, II y III (1962-1972) (1972-1983) (19641988). Una prueba de la regularidad y el constante flujo de sus páginas críticas es el hecho de que configuran series que se extienden a lo largo de muchos años. La más importante y conocida es la titulada "Piedra de toque", inicialmente publicada en Caretas y luego en El Comercio de Lima y El País de Madrid, que aparece semanalmente y es reproducida en varios periódicos de todo el mundo. Esta serie puede considerarse la más influyente porque suele dar un testimonio inmediato de sus lecturas, viajes, encuentros y andanzas con personajes conocidos o desconocidos y, sobre todo, de su posición personal frente a los grandes acontecimientos políticos y culturales —en el más amplio sentido de la palabra - que transforman nuestro tiempo. Leer estas crónicas y reflexiones es un modo de apreciar cómo va cambiando y definiéndose el perfil intelectual de Vargas Llosa ante las polémicas y espinosas cuestiones que la realidad le presenta. El título de la recopilación Contra viento y marea, que recoge parte de esta serie, subraya el hecho de que muchas de sus páginas expresan un pensamiento crítico que no teme contradecir opiniones mayoritarias y defender causas no siempre populares.

Su pensamiento político, sin duda, ha sufrido giros sustanciales. Sin que ése haya sido su propósito, su hábito de dejar testimonio de todo lo que pasa a su alrededor y de tomar posiciones al respecto ha dejado un continuo registro - casi como una especie de diario o memoria intelectual- de los hechos que modelan nuestro proceso histórico y sus momentos clave. No hay, pues, que rebuscar mucho para hallar los textos que podrían incriminarlo: llevan su firma, son, como siempre, explícitos y no han sido ocultados por el autor. Están a la vista para cualquiera que desee consultarlos en Contra viento y marea, cuya primera edición cubre un período de crítica importancia: 1962-1982. En el 
prólogo de esa edición, después de preguntarse por qué reúne estos textos que, por su naturaleza misma, "el tiempo ha maltratado sin piedad", nos explica:

Exhibo esta suma de contradicciones, ingenuidades, equivocaciones y alguna que otra intuición feliz sin arrogancia ni arrepentimiento, con melancolía por las ilusiones que se llevó el viento y hasta por esos adjetivos solemnes y exagerados que la pasión explica y que la prisa periodística solía desviar del blanco. En un sentido, esta colección puede leerse como un documental sobre los mitos, utopías, entusiasmos, querellas, esperanzas, fanatismos y brutalidades entre los que vivía un latinoamericano entre las décadas del sesenta y setenta; esa atmósfera política e intelectual que todos los escribidores contribuimos y nuestra pluma a purificar o enrarecer (me temo que sobre todo esto último) $)^{2}$.

En este revelador pasaje la palabra clave es exhibo, pues subraya el hecho poco común de que el propio autor presenta, en vez de enmascararlas o borrarlas, las pruebas que contra él pudiera levantar el lector al notar los cambios de su pensamiento crítico. Resulta evidente que su intención es estimular las discrepancias y el debate, pese a la ardiente convicción que alientan muchas de estas páginas. Su expediente está a la vista y constantemente abierto al cuestionamiento, propio o ajeno.

Seguramente, la primera gran crisis de la evolución de su pensamiento crítico se produce en 1970 a raíz del tristemente célebre "caso Padilla" en Cuba, que no sólo conmovió profundamente su conciencia intelectual, sino que originó un gran cisma entre los escritores, artistas y pensadores latinoamericanos y europeos que habían defendido la causa de la Revolución Cubana. Hay que recordar que Vargas Llosa había sido, hasta entonces, uno de ellos, y de los más visibles, activos y entusiastas. Esto incluía su apoyo táctico a los movimientos guerrilleros fomentados y financiados por Cuba en toda América Latina. Así se explica que el autor condenase al gobierno de Fernando Belaúnde, elegido democráticamente, por su política represiva de los brotes armados que surgieron en el Perú en los años sesenta; léase, por ejemplo, la "Toma de posición"3 que firmó en París junto con Julio Ramón Ribeyro

${ }^{2}$ Mario Vargas Llosa, Contra viento y marea, Vol. I, pp. 9-10. En adelante este libro será citado bajo las siglas CVM.

${ }^{3}$ Mario Vargas Llosa, CVM, Vol. I, pp. 9-10. 
y otros. Su relación solidaria con Cuba comienza en enero de 1965 , cuando viaja a La Habana invitado como miembro del jurado de novela de los premios Casa de las Américas; en verdad, había estado allí antes, en octubre de 1962, enviado por la Radio-Televisión Francesa a cubrir la llamada "crisis de los misiles". Después volvió varias veces más en los años siguientes, en calidad de jurado de esos premios y como miembro del consejo de redacción de la revista Casa de las Américas, al que perteneció hasta abril de 1971.

Ésa es la fecha en la que renunció formalmente, en carta a Haydée Santamaría ${ }^{4}$, a la que siguió otra carta colectiva firmada por él y un numeroso grupo de intelectuales latinoamericanos, en la que se condenaba la "confesión" de Heberto Padilla y su manipulación por el régimen cubano como "una penosa mascarada de autocrítica [que] recuerda los momentos más sórdidos de la época del estalinismo"s; con este último documento se formaliza el cisma al que hice referencia antes y cuyas repercusiones históricas serían largas y profundas.

Un período de desilusión, crítica y distanciamiento ideológico comienza allí; Vargas Llosa se coloca a la cabeza entre quienes ya no verán más a la revolución castrista como un modelo posible. Su rechazo radical tiene mucho que ver con el impacto que le produjeron las revelaciones personales de Jorge Edwards sobre su breve misión diplomática en la isla, y luego la lectura de su libro testimonial Persona non grata (1972), que le mostraron la cara oculta del sistema cubano. Algo que puede decirse de su indignación — en verdad, su asco - ante todos estos acontecimientos es que su desengaño fue proporcional a su fe revolucionaria, por lo que su caso se parece mucho a los que tiempo atrás protagonizaron escritores europeos, como Gide, Orwell, Koestler y Sartre cuando encararon la innegable realidad del totalitarismo tras la máscara socialista: son una forma de reacción visceral, llena de frustración e invencible aversión a lo que hasta ese momento habían defendido. La revulsión moral de Vargas Llosa se debe a que el asunto comprometía gravemente un área en la cual era incapaz de hacer la menor concesión: la del respeto a la libertad de expresión, la dignidad del escritor y el derecho a la crítica, que son los pilares fundamentales de su propio credo intelectual.

\footnotetext{
${ }^{4}$ Mario Vargas Llosa, CVM, Vol. I, pp. 164-165.

${ }^{5}$ Mario Vargas Llosa, CVM, Vol. I, p. 166.
} 
El 11 de agosto de 1967, en su discurso de recepción del Premio Rómulo Gallegos por La casa verde, había invocado la figura, entonces muy poco conocida fuera del Perú, del poeta vanguardista Carlos Oquendo de Amat, quien adhirió, reafirmando su fe revolucionaria, a la causa republicana española y murió en medio de la guerra civil. Por su lado, Vargas Llosa reafirma que "la literatura es fuego", pues es un arma de irreducible rebeldía que ninguna sociedad podía esperar fuese dócil a su seducción o a sus amenazas.

América Latina debe recordar también la amenaza que se cierne sobre ella, el duro precio que tendrá que pagar por la cultura. Nuestras sociedades deben estar alertadas: rechazado o aceptado, perseguido o premiado, el escritor que merezca este nombre seguirá arrojándoles a los hombres el espectáculo no siempre grato de sus miserias y tormentos ${ }^{6}$.

Es interesante recordar que, en ese momento, su apasionada advertencia se entendió sobre todo como dirigida contra regímenes como el venezolano, entonces en muy tensa relación con Cuba por el respaldo que ésta brindaba a los grupos armados que operaban en el país; pero sus palabras, inesperadamente, resultarían proféticas sobre lo que, unos años después, ocurriría en la isla con el "caso Padilla". Fue así como Vargas Llosa comprendió definitivamente que la literatura (y la actividad intelectual en general) era un gran poder moral contra el absolutismo del poder político de cualquier signo; la literatura era, en verdad, fuego. Jamás renunciaría a defender y ejercer ese poder, y cada vez lo haría de modo más sistemático.

El otro momento clave en la evolución de su pensamiento crítico ocurre en los años inmediatamente anteriores a 1990 y está estrechamente vinculado con la situación que vivía en esos momentos el Perú. El país se debatía en una de sus peores crisis políticas: por un lado, la llamada "guerra popular" desatada por el grupo terrorista Sendero Luminoso, que no fue sino una gran matanza (la cifra oficial es de 59.000 muertos, la mayoría pobladores o campesinos indígenas, sin olvidar que muchos fueron víctimas de la no menos brutal represión militar); por otro, la situación económica bajo el presidente aprista Alan García, en su primer gobierno, había hundido al país en la ruina, con una hiperin-

${ }^{6}$ Mario Vargas Llosa, CVM, Vol. I, p. 136. 
flación totalmente fuera de control que sumió en la pobreza y el hambre a capas sociales que hasta entonces no habían sufrido esos males. El Perú parecía estar al borde del abismo porque esa situación (agravada por la corrupción) daba un oportuno argumento a la sanguinaria campaña de Sendero Luminoso: ante el fracaso del poder legítimo no cabía otra opción - tal era el razonamiento- que la violencia revolucionaria.

En ese contexto, el gobierno de Alan García decidió suspender el pago de la enorme deuda externa (con lo cual el país se convertía en una especie de renegado en el ámbito financiero internacional) y anunció su propósito de nacionalizar la banca. Vargas Llosa había hecho varios inequívocos pronunciamientos sobre las matanzas de Sendero y sobre la errónea política económica de García. Al convertirse, así, en una voz muy influyente como crítico del gobierno, empezó a ganarse adhesiones de amplios sectores de la oposición y entró de lleno al debate interno. En otras palabras, pasó a jugar un papel decisivo en la evolución del proceso político peruano en los últimos años del régimen aprista.

No fue, pues, del todo inesperado que, ante el anuncio de la nacionalización de la banca, Vargas Llosa lanzase un manifiesto que tuvo una enorme repercusión en la opinión pública del país; lo que sí resultó inesperado fue que con ese documento el autor apareciese como una opción real en la contienda electoral para suceder a García. Como Vargas Llosa ha contado en detalle esas circunstancias y el desenlace de su propia campaña presidencial en el citado Pez en el agua, no es necesario abundar en cómo y por qué se produjo su derrota electoral; sus circunstancias y razones son bien conocidas por todos.

Lo importante es señalar que tras esta experiencia su interés por la política pasó a tener una suprema importancia en su agenda personal, en sus lecturas, en sus preocupaciones intelectuales, en el modo como encaraba la historia presente. Es decir, la derrota que sufrió en 1990 y que debió tener un efecto traumático en un intelectual del todo novato en el campo de la política como práctica cotidiana, le enseñó que el ámbito en el que podía jugar un papel más afín a su experiencia y conocimiento era otro: el de ocupar un puesto en la tribuna internacional donde se planteaban y debatían las más graves y urgentes cuestiones que nuestro mundo enfrenta cada día. Los textos de "Piedra de toque" y otras notas periodísticas se volvieron cada vez más documentos de su pensamiento político.

Aprovechando los instintos y reflejos que su incursión personal en la política concreta le había dejado, pasó a ser — todavía más 
intensamente que antes - un testigo, un interlocutor comprometido, una conciencia crítica de todo lo que pasaba a su alrededor, otra vez un reportero pero en un escenario sin fronteras. $\mathrm{Y}$ así asumió una enorme responsabilidad: la de tomar posiciones muchas veces incómodas porque no siempre le ganan simpatías. En las dos últimas décadas, por lo menos, ha operado muchas veces como un francotirador solitario e irritante que prefería hablar y no guardar confortable silencio.

Uso deliberadamente la palabra francotirador, la misma que, en un artículo de 1974 ("Un francotirador tranquilo"7), aplicó a Jorge Edwards, autor de Persona non grata, porque el escritor chileno adopta en su testimonio cubano una posición muy personal y riesgosa, al margen de partidos o grupos de opinión reconocibles; lo prueba el hecho de que el libro fue censurado por Castro y por Pinochet. Se trata de una crítica "al descubierto", cuyas consecuencias recaen íntegramente sobre él.

De modo similar, Vargas Llosa está empeñado en una campaña azarosa, constante y solitaria en defensa de un conjunto de convicciones que, siendo muy firmes, están sujetas a las reglas impredecibles de un mundo siempre en transición, donde todo vive sujeto a un interminable proceso de examen y revisión, que son las operaciones propias del género ensayístico en su búsqueda de la verdad como algo relativo y perfectible.

Un ejemplo notable de su pasión por hallar esa verdad mediante el reportaje de actualidad son las crónicas escritas tras sus viajes a zonas de conflicto en el Medio Oriente: Israel, los territorios palestinos, Irak, Líbano, etc. Por lo menos dos de esas series han sido publicadas en forma de libro: Diario de Irak (2004) e Israel/Palestina: Paz o guerra santa (2006). En el primero, el lector puede observar la evolución de sus puntos de vista sobre esa guerra, que al principio había apoyado, pero a la que luego (el detonante fue el escándalo por los abusos y torturas sufridos por los prisioneros de Abu Ghraib) hizo fuertes reparos y críticas al descubrir allí realidades de la campaña política y militar que desconocía. Las repercusiones de las crónicas reunidas en el segundo libro han sido más polémicas y agresivas porque, pese a que en el prólogo reafirma, inequívocamente, que su "postura a favor de la existencia de Israel y de su derecho a defenderse de los fanáticos [...] no ha variado un ápice", rechaza, con igual firmeza, "el chantaje al que recurren muchos fanáticos de llamar antisemita a quien denuncia los

${ }^{7}$ Mario Vargas Llosa, CVM, Vol. II, pp. 201-212. 
abusos y crímenes que comete el Gobierno de Israel" contra el pueblo palestino ${ }^{8}$.

La humillante e intolerable situación a la que ese gobierno tiene sometidos a los palestinos es descrita con tanta minucia como indignación, especialmente en las crónicas tituladas "El horror se llama Hebrón"9 y "Ratoneras humanas"; copio el comienzo de esta última:

Del millón trescientos mil palestinos que habitan en los 365 kilómetros cuadrados de Gaza - el lugar de mayor densidad demográfica de Oriente Próximo-, más de dos tercios se apiñan en las ratoneras humanas que son los campos de refugiados, producto de la llamada "guerra de independencia" de Israel, en 1948, cuando unos ochocientos mil palestinos fueron desarraigados de sus aldeas y aventados al exilio ${ }^{10}$.

No se pueden leer líneas como éstas sin sentir la misma conmoción moral que refleja el autor: son terribles verdades que el tiempo ha ido borrando de la conciencia y la memoria del público general. La misma incomprensión han provocado en los sectores israelíes más recalcitrantes ciertas afirmaciones radicales hechas en su artículo "Israel y los matices" (EL País, 16 de julio, 2006), posterior a las crónicas recogidas en Israel/Palestina. Comentando las ideas liberales del historiador judío Illan Pappe, Vargas Llosa desliga el destino histórico de Israel de la tradición bíblica y, por ende, de la doctrina sionista:

Para mí, el derecho a existir de Israel no se sustenta en la Biblia, ni en una historia que se interrumpió hace miles de años, sino en la gestación del Israel moderno por pioneros y refugiados que, luchando por la supervivencia, demostraron que no son las leyes de la historia las que hacen a los hombres, sino éstos, con su voluntad, su trabajo y sus sueños, los que le marcan a aquéllas unas pautas y una dirección.

\section{Y agrega:}

Ahora bien, para que Israel tenga un porvenir seguro y aceptado por sus vecinos, debe encontrar un modo de coexisten-

${ }^{8}$ Mario Vargas Llosa, Israel/Palestina: Paz o guerra santa, 2006, pp. 10-11. En adelante este libro será citado bajo las siglas $I P$.

${ }^{9}$ Mario Vargas Llosa, $I P$, p. 93.

${ }^{10}$ Mario Vargas Llosa, IP, p. 93. 
cia con los palestinos. Y contra esta coexistencia conspira esa ocupación de Cisjordania que se prolonga indefinidamente y que ha convertido a Israel en un país colonial [...].

Entendiendo que estas afirmaciones constituían inaceptables herejías, los israelíes ultraortodoxos perdieron de vista precisamente los "matices" y expresaron su total repudio. Pero otros métodos más sutiles se usaron para tratar de acallarlo: en el citado prólogo a Israel/Palesti$n a$, el autor da una idea del enorme poder que los intereses judíos tienen sobre la libre difusión de opiniones disidentes como la suya: revela que sólo un diario italiano publicó la serie completa de sus crónicas; otros, como Le Monde, publicaron sólo fragmentos de ella, pese a haber adquirido los derechos para reproducirla entera ${ }^{11}$. Todo esto muestra lo que puede ocurrir a los que practican el pensamiento libre y sin prejuicios ni tabúes en un mundo dominado por ellos.

Algo más a propósito de sus reportajes de actualidad que me parece importante destacar: representan para el autor —al margen de su función informativa - un sucedáneo de la aventura, de la acción directa, ese aspecto tan dominante en gran parte de su obra narrativa. Escribir esos reportajes es una forma vicaria de vivir lo que sólo presencia como testigo. Ser un hombre de letras no le basta y quisiera ser también un protagonista o militante de los hechos que presencia y narra. En la crónica "Soldados del imperio" (El País, 28 de enero, 2007) invoca el ejemplo de Koestler y Orwell al comentar el libro Imperial Grunts, que cuenta las experiencias del reportero Robert D. Kaplan al lado de las llamadas "fuerzas especiales" de Estados Unidos; las que, repartidas por muchos lugares del mundo, de Colombia a Mongolia, cumplen misiones secretas de alto riesgo, más de aventureros que de militares. Al subrayar la trascendencia de esos testimonios de primera mano, que aparte de "esclarecer hechos dramáticos de la vida contemporánea, se leen con el placer y la ansiedad que producen las buenas novelas", se trasluce la admiración, la fascinación, casi la envidia, que siente por un reportero que viaja a los lugares más peligrosos y que comparte el foco de acción con hombres anónimos que están vivos hoy y pueden morir mañana, sin dejar huellas, tan clandestinamente como actuaron. Parecería que siente la irresistible tentación de no ser un mero testigo y ser parte de lo que presencia; escribir sería entonces la forma más alta de actividad intelec-

${ }^{11}$ Mario Vargas Llosa, $I P$, p. 10. 
tual. En nuestra lengua tal vez no haya otros personajes comparables a los suyos que los de Juan Goytisolo sobre el mundo político y cultural musulmán, autor con quien Vargas Llosa tiene algunas coincidencias y varias discrepancias.

Pese a la constante evolución de su pensamiento crítico y las revisiones, por las que va pasando la campaña que cada día libra, hay un conjunto de principios fundamentales que le dan una estructura y un perfil muy reconocibles. Señalo aquí cuatro de ellos: el apoyo al modelo neoliberal en economía y a la correspondiente aspiración "globalizadora" del desarrollo; la defensa del sistema democrático para evitar los males del populismo y el autoritarismo; el rechazo frontal del nacionalismo; la reafirmación de la sociedad multicultural que equilibre el respeto a las minorías (de cualquier tipo) y la lucha contra el fanatismo (de cualquier clase). Puede verse de inmediato que son propuestas interrelacionadas que podrían resumirse en un principio rector, en el cual Vargas Llosa no hace ninguna concesión: la libertad del individuo frente al Estado y la condena de cualquier manifestación de prejuicio o censura, desde la política a la sexual. Examinarlas a fondo excedería las dimensiones de un trabajo como el presente; por eso, me limitaré a hacer sólo algunos apuntes sobre los alcances y problemas que presentan.

Quizá la cuestión que más ataques y disgustos le ha causado es la primera — su entusiasta defensa del modelo neoliberal-, pues aparece como un completo vuelco del escritor en su fe socialista que, hasta su ruptura con Cuba, había manifestado de muchos modos. Esos vuelcos en la adhesión política son frecuentes en la historia moderna, y el de Vargas Llosa es sólo uno más de ellos. Las dos experiencias que antes he señalado en la formación de su pensamiento político (Cuba y su propia campaña electoral de 1990) son vivencias que han modelado su ideología y provocado una profunda aversión por cualquier forma de sistema o ideología que recorte el derecho a que los individuos decidan quién y cómo los gobiernen. Es la mínima garantía de civilidad y racionalidad en la vida política en cualquier país del mundo. Eso permite el balance ideal para que alcanzar la justicia no sacrifique la democracia ni viceversa.

Leyendo sus crónicas y artículos, en los que ha reiterado una y otra vez tales convicciones, esa fórmula ideal a veces se ve en aprietos cuando se desciende al terreno de los hechos, sobre todo en América Latina, precisamente desde donde suelen surgir las voces más críticas 
a su posición. A los que claman por cambios sociales profundos e inmediatos sin miramientos a las formalidades democráticas, el autor les recuerda lo que la historia enseña: la opción revolucionaria, aunque parezca atender esa urgencia, sólo retrasa más la posibilidad de alcanzar la justicia social.

Aquí cabe hacer un comentario sobre la relatividad histórica del concepto "democracia". Aunque el término sea el mismo, no es igual su significado en países como Inglaterra o Francia que en México, Guatemala o El Salvador, donde se apoya precisamente en un grado intolerable de injusticia. Es decir, hay una apariencia democrática que enmascara o distorsiona los verdaderos problemas sociales y, en el fondo, contribuye a postergar indefinidamente su solución, lo que pone a países como ésos en situaciones extremas y favorece los cíclicos estallidos de violencia o anarquía. Podría afirmarse que hay democracias que operan contra la democracia misma, que incurren en crímenes y otros actos repudiables. A sus respectivos pueblos es muy difícil pedirles que apoyen o respeten esas “democracias” y que además sean pacientes cuando sufren hambre, abusos o carencias básicas. Recordemos que en los años de la guerra civil salvadoreña, su "democracia" aceptó un pacto militar encubierto con la administración Reagan y tuvo como brazo armado a escuadrones de la muerte, cuya violenta herencia aún se siente hoy. No olvidemos tampoco que fue el fracaso histórico de la formalidad democrática en Venezuela lo que llevó al poder, paradójicamente por vía electoral, a Hugo Chávez, la peor expresión de demagogia populista. Hoy es justamente el descontento mayoritario con el viejo sistema institucional el que aún le brinda el apoyo de un buen sector popular; por lo menos la mitad del electorado no quiere volver a él.

Claro que se trata de una cuestión asociada con el estado relativamente incipiente o inmaduro de nuestros sistemas democráticos, pero el hecho concreto es que no funcionan y se vuelven muy poco defendibles. En esencia, creo que la democracia es un simple medio (imperfecto, pero el mejor o el menos malo), no un absoluto y ni siquiera un fin en sí mismo: depende de sus logros, no de sus formas, muchas veces engañosos subterfugios para dar un decente barniz al control que ciertas clases políticas mantienen sobre el resto de la sociedad.

Algo parecido podría decirse del modelo económico neoliberal, asociado con el democrático, que, en principio, permite la igualdad de oportunidades a través de la libre competencia, pues los que nada o 
poco tienen no pueden concurrir y participar en ese promisorio mercado mundial sin trabas ni limitaciones. El fondo de la cuestión está, por lo tanto, en la justicia de la democracia y del mercado o, dicho de otro modo, en trasladar el verdadero juego democrático a los mecanismos económicos para evitar que imperen sólo las ciegas reglas del lucro. El énfasis debe estar puesto en asegurar que ambos órdenes no se justifican si son fórmulas vacías, que debemos respetar como intocables aun si contradicen sus objetivos y promesas. Por supuesto, éste es uno de los más arduos problemas políticos que existen: si la democracia y el libre mercado no funcionan y la revolución es un peligroso sofisma, ¿qué alternativa nos queda? ¿Qué matiz o variante del socialismo democrático es viable o la más eficaz? Quizá haya que agradecerle a Vargas Llosa haber puesto estos temas en primer plano del debate político.

Otro tema de interés es el del nacionalismo, que el autor ve como una fuerza retrógrada y opuesta a la apertura "globalizadora". Si atendemos a la experiencia política de América Latina, es cierto que el nacionalismo estrecho ha traído los males de la balcanización del continente, los conflictos armados, las tensiones fronterizas, las economías de enclave y otros. El ideal nacionalista trae generalmente anexo una visión provinciana y mezquina, que ve lo extranjero con desconfianza, como un influjo nefasto al que hay que cerrarle el paso. En los peores casos puede conducir a la xenofobia más hirsuta y a ideas de superioridad racial, como ocurrió con el nazismo, ejemplo que Vargas Llosa invoca con frecuencia. Para un ardiente defensor de la "sociedad abierta" como él, el nacionalismo es un mal que debemos desterrar.

Todo eso es esencialmente cierto, pero en algunos casos el nacionalismo puede resultar, ya que no deseable como ideal, inevitable como necesidad histórica para la existencia de un pueblo, sobre todo cuando su vecino es mucho más poderoso que él. ¿Existiría hoy el pueblo palestino, que con justicia defiende Vargas Llosa, sin su fe nacionalista? Otro caso paradigmático y mucho más cercano a nosotros es el de México, cuya frontera con Estados Unidos - como ha reconocido Octavio Pazlo ha definido como nación; la otra opción al nacionalismo habría sido sencillamente la de desaparecer y ser anexado por su poderoso vecino, como ha ocurrido en cierta forma con Puerto Rico. Naturalmente, el riesgo es que ese mismo nacionalismo puede encerrarlo en un callejón sin salida de caudillos demagógicos que agitan oportunamente el más crudo antinorteamericanismo. 
Pero el argumento sobre el nacionalismo que me interesa proponer no es el geopolítico, sino el cultural. En ese plano, el afán nacionalista puede haber dado algunos frutos literarios contrahechos o pintorescos, aunque, en manos de algunos, sea también un impulso de gran fuerza creadora. No olvidemos que está en la base de los poemas homéricos y de la épica europea. Pero si salimos del campo literario y entramos en el de la música, los ejemplos son de una abundancia, variedad y continuidad aplastantes. ¿Qué sería de la música culta sin la inspiración que hallaron en motivos populares, tradicionales y folklóricos grandes compositores como Beethoven, Liszt, Richard Strauss, Smétana, Dvorák, Sibelius, Bartok, Stravinsky, Falla, Turina, Katchaturian, Copland, VillaLobos, Ginastera y decenas de otros? Cabe afirmar que, en ésta y otras áreas, hay un "mal" y un "buen" nacionalismo, especialmente cuando éste carece de pretensiones de superioridad de lo propio sobre lo ajeno.

No menos interesante y polémico es el tema del multiculturalismo en sociedades como las nuestras, que, en las últimas décadas, se han visto inundadas por millones de inmigrantes, cuyas características propias no hacen muy fácil su inserción en la cultura metropolitana. ¿Es la total asimilación lo mejor para todos? ¿Debe respetar la sociedad anfitriona las diferencias del estilo de vida y de creencias religiosas de la cultura huésped, aun si contradicen o afectan las suyas? ¿Y cómo satisfacer las aspiraciones de las comunidades emigradas a la educación y a otros servicios sociales básicos, si implican valores sustancialmente distintos? ¿Cómo hacer de los recién venidos "nuevos ciudadanos" que funcionen bien en un contexto ajeno sin dejar de ser diferentes, es decir, ellos mismos?

Las consecuencias de las actitudes y medidas que al respecto se adopten son de enorme importancia para todos. Es bueno recordar que la primera vez que Vargas Llosa se planteó estos problemas no fue como ensayista o periodista, sino como novelista. En La guerra del fin del mundo retomó el asunto que dio origen a Los sertones, de Euclides Da Cunha, uno de los clásicos de la literatura brasileña. El libro narra el histórico enfrentamiento entre un sector tradicional de pobladores sertanejos, quienes, alentados y dirigidos por un líder religioso milenarista, se rebelan contra el poder central empeñado en un esfuerzo modernizador para incorporar esa remota región al nuevo orden republicano.

Entretejiendo un vasto tapiz polifónico que muestra a las plurales fuerzas envueltas en el conflicto, Vargas Llosa señala — como antes 
llamó la atención Sarmiento en el Facundo (1845) — el insalvable abismo que puede abrirse entre las formas arcaizantes y las que buscan el cambio civilizador. Al margen de los intereses menudos y espurios que se entremezclan en ese marco de la rebelión sertaneja, ¿quiénes tienen la razón: los que defienden el "bárbaro" mundo del pasado o los que representan el orden "ilustrado" que puede redimirlos de su propio atraso? ¿Atraso o progreso según quiénes?

Contestar tales preguntas de modo satisfactorio para todos es seguramente imposible. El siempre activo debate antropológico, etnológico y cultural de nuestros días sigue echando luz (y complicando, de paso, la posibilidad de fáciles soluciones) sobre estos asuntos, cuya complejidad y urgencia requieren coraje y visión clara. El resurgimiento del poder político y cultural de los pueblos musulmanes en todo el mundo, por ejemplo, ha exacerbado la cuestión porque esos poderes se asocian ahora con el fanatismo religioso y además con la violencia terrorista, fenómenos que hacen aún más difícil entender y apoyar la causa que defienden. El autor ha intentado dar una respuesta, o una serie de respuestas, a esos graves problemas, respuestas que tienen ellas mismas aristas polémicas.

Su defensa del Estado laico es un aspecto esencial de su posición. Entiende que las prácticas religiosas son legítimas expresiones en público siempre y cuando no interfieran con otras, no quieran imponerse sobre ellas o alcanzar un trato preferente del Estado, que debe mantener su neutralidad frente a todas; en caso contrario, deben limitarse al fuero privado o comunitario. Así como el Estado debe respetarlos a todos por igual, ellos deben respetar esa neutralidad.

En el campo educativo este problema es particularmente agudo y ha generado situaciones muy tensas y reacciones violentas. Un caso específico es el uso del velo que las jóvenes musulmanas querían llevar en las aulas de las escuelas públicas en Francia y otros países europeos. Según el autor, el derecho a usar la prenda cesa justo en las puertas de esas escuelas, lo que para los más celosos guardianes de la tradición musulmana es ofensivo.

Hay otras tradiciones y costumbres que la civilización moderna se ve forzada a rechazar porque entran en conflicto con principios y derechos humanos básicos. Un caso flagrante de eso es el de la ablación genital femenina que se practica en ciertos pueblos musulmanes del Medio Oriente y de África. Su rechazo en el resto del mundo se debe no 
sólo a que es una ofensa suprema a la dignidad de la mujer y a su derecho al placer sexual, sino también por razones médicas, pues la ablación produce graves lesiones permanentes que muchas veces resultan mortales. El problema es que prohibir esa práctica - además de difícil, porque suele ser clandestina y sin control externo- podría considerarse unilateral, pues la práctica judía de la circuncisión, no menos violenta y sin justificación científica, es aceptada sin protestas de ningún tipo en muchos países. Esto confirma que lo que es repulsivo o retrógrado para algunas culturas no lo es para otras; ése es el sutil punto en el que la posición de Vargas Llosa — sin duda, razonable y perfectamente compartible - ofrece un constante flanco propicio al ataque y la condena de ciertos sectores que la ven como una forma de imposición de una cultura sobre otra, como una sanción moral que no se aplica a todas por igual.

Su infatigable batalla por la libertad, la democracia, la tolerancia y los derechos del individuo frente a las cada vez más poderosas maquinarias estatales configura, en verdad, una nueva utopía para el mundo moderno, una de las más consistentes que haya elaborado un intelectual latinoamericano desde la segunda mitad del siglo XX. Esa utopía es, como bien sabe él, un sueño inalcanzable, pero un sueño necesario porque alberga la negativa a aceptar el mundo tal como es y reafirma la esperanza de que nuestras sociedades sean perfectibles, cada vez más armónicas, más humanas. Es una quimera que se reformula una y otra vez, una tarea de Sísifo, ya que cada día la realidad se empeña en destruir todo lo que se ganó en la jornada anterior.

Es irónico haber usado esa imagen del mundo clásico que todos asociamos con la obra de Camus, ya que la utopía de Vargas Llosa lo ha llevado, inevitablemente, a cumplir la función del escritor "comprometido" que modeló Sartre, con quien el autor tenía una estrecha afinidad en sus años formativos; luego pareció seguir el ejemplo menos militante de Camus $^{12}$. Puede afirmarse que mientras su narrativa se ha alejado por completo de sus iniciales connotaciones sartrianas, su obra crítica ha dado un giro completo y ha vuelto - en medio de visibles diferencias-a ser "comprometida".

El mejor testimonio de ello es uno muy reciente y de él mismo: su artículo titulado "Günter Grass en la picota" (El País, 27 de agosto,

12 Véanse los textos reunidos bajo el rubro "Entre Sartre y Camus" al comienzo de CVM, Vol. I, pp. 11-63. 
2006). En términos bastante benévolos — si se recuerda que años atrás tuvo una dura polémica con el escritor alemán a propósito de la posición de éste sobre América Latina—, hace una defensa de Grass, quien era, en esos momentos, blanco de muy fuertes ataques tras revelarse que había pertenecido a las Waffen SS en la época de Hitler. El pasaje pertinente es largo, pero conviene citarlo en su integridad:

Tal vez el formidable escándalo que ahora rodea su figura tenga mucho que ver con esa función de "conciencia moral" de la sociedad que él se impuso y que ha mantenido a lo largo de toda su vida, a la vez que desarrollaba su actividad literaria. No me cabe duda de que Günter Grass es el último de esa estirpe a la que pertenecieron un Victor Hugo, un Thomas Mann, un Albert Camus, un Jean-Paul Sartre. Creían que ser escritor era, al mismo tiempo que fantasear ficciones, dramas o poemas, agitar las conciencias de sus contemporáneos, animándolos a actuar, defendiendo ciertas opciones y rechazando otras, convencidos de que el escritor podía servir también como guía, consejero, animador o dinamitero ideológico sobre los grandes temas sociales, políticos, culturales y morales, y que, gracias a su intervención, la vida política superaba el mero pragmatismo y se volvía gesta intelectual, debate de ideas, creación.

Estas líneas son, más que un retrato de Günter Grass, un autorretrato de Vargas Llosa y una cabal explicación de por qué ha elegido ser un activo testigo del mundo, fiel a una pasión por la realidad que se despertó en sus años de oscuro reportero adolescente en La Crónica, y que luego lo impulsó a escribir novelas. Imaginar y testimoniar son dos funciones que han llegado a ser, para él, complementarias: se necesitan la una a la otra con igual fuerza.

\section{REFERENCIAS}

Gargurevich, Juan. Mario Vargas Llosa. Reportero a los quince años. Lima:

Fondo Editorial de la Universidad Católica del Perú, 2005.

Vargas Llosa, Mario. Contra viento y marea [CVM]. Vol. I. Barcelona: Seix Barral, 1983.

- Contra viento y marea [CVM]. Vol. II. Barcelona: Seix Barral, 1986.

- Israel/Palestina: Paz o guerra santa. [IP]. Lima: Aguilar, 2006. "Israel y los matices". El País, 16 de julio 2006. "Günter Grass en la picota”. El País, 27 de agosto 2006. “Soldados del imperio”. El País, 28 enero 2007. 